\title{
Direct Incorporation of Butyl Stearate as Phase Change Material into Concrete for Energy Saving in Buildings
}

\author{
Kemal Cellat, Beyza Beyhan, Berk Kazanci, Yeliz Konuklu, and Halime Paksoy
}

\begin{abstract}
Buildings are one of the largest energy consumers in the developed countries. The building sector represents $40 \%$ of the total energy consumption in the world and is responsible for the $30 \%$ of the annual greenhouse gas emissions. In recent years, various studies have investigated reducing energy consumption in buildings. One of these studies under development is using phase change materials (PCMs). PCMs are substances that melt and freeze at a nearly constant temperature, and during this phase change process, they release and absorb significant amounts of thermal energy. Using PCMs in buildings not only helps to reduce energy consumption, but also smooth the temperature distribution inside the building.

In this study, using butyl stearate as PCM for energy saving in building applications was investigated. Results showed that butyl stearate has suitable thermal properties to maintain thermal comfort in buildings and is a promising phase change material.
\end{abstract}

Index Terms-Buildings, energy saving, phase change materials.

\section{INTRODUCTION}

The growing population and industrial needs are major source of global energy consumption. The current global dependence on fossil fuels for energy production presents not only economical, but also environmental concerns. Finite sources of fossil fuels and increasing levels of greenhouse gas emissions necessitate to utilise renewable energy sources more [1]. Renewable energy sources such as solar, wind, hydropower and biogas show strong potential to meet global energy requirements in a sustainable way. In any case, to face demand fluctuations of renewable energy systems, using energy storage has become more important than ever [2]. Thermal energy storage (TES) is considered as one of the most important technologies and receiving a lot of attention for thermal applications ranging from heating to cooling in buildings with renewable, continuous, and adaptable supplies. TES already became the second largest energy storage system in the USA [3]. Utilization of thermal energy storage is expected to almost double in 2015 [4].

Manuscript received July 23, 2015; revised December 14, 2015. This work was financially supported by TUBITAK under project number 111M557, Çukurova University BAP Project No FDK-2015-3278, and FYL-2015-4447 and sponsored by Kambeton Co.

Kemal Cellat, Beyza Beyhan, Berk Kazanci, and Halime Paksoy are with the Faculty of Arts and Sciences, Department of Chemistry, Cukurova University, 01330, Saricam Adana, Turkey (e-mail: kcellat@gmail.com, beyzabeyhan@gmail.com, berk_kazanci@hotmail.com, hopaksoy@cu.edu.tr).

Yeliz Konuklu is with Nigde University, Nanotechnology Application and Research Center (NRC), Nigde, Turkey (e-mail: ykonuklu@nigde.edu.tr).
Phase change materials (PCMs) are substances that are capable of storing large amounts of thermal energy as latent heat during their phase transition. The possible use of PCM in buildings is taking attention due to the large energy storage density and nearly isothermal nature of the PCM. In a passive system, PCM absorbs heat from solar radiation during daytime by melting and, releases that heat when the temperatures cool down at night. As a result of this process, indoor temperature swings can be reduced, thus not only thermal comfort is improved but also the building's energy consumption is reduced. As the PCMs are continuously subjected to change phase from solid to liquid in solar cycles during the day, they need to be kept in containers. In building integrated latent heat storage applications, PCMs can be contained in a porous construction material such as concrete [5], gypsum [6], plasters [7], brick holes [8], textured finishes etc.

Voelker et al. [9] developed the gypsum board with integrated microencapsulated PCM that has melting range of $25-28^{\circ} \mathrm{C}$. Two identical test rooms were built, and in the first one, walls were covered with PCM plaster boards and in the second one with ordinary plaster boards. Results showed that a reduction of the peak temperature up to $4 \mathrm{~K}$ in comparison to the reference room could be achieved.

Castellón et al. [10] constructed nine identical cubicles in Lleida, Spain. Two with concrete, five with conventional brick and two with alveolar brick. The cubicles were equipped with a heat pump to maintain indoor temperature at $24^{\circ} \mathrm{C}$. Their electricity consumption in a summer week was reduced by up to $15 \%$ and $17 \%$ by adding PCM to cubicles containing plain and alveolar brick, respectively. The authors also claimed that the performance could be further improved by optimizing the PCM melting temperature according to the climate conditions.

He et al. [11] studied preparation and characteristics of a composite phase change material produced by incorporating polynary fatty acid eutectic mixture into sludge ceramsite. Five different kinds of polynary fatty acid eutectic mixtures were used as PCM and one of them, suitable for regulating room temperature, was absorbed into sludge ceramsite by vacuum. Temperature regulation effect was tested by building models. Model experiments showed that the prepared composite PCM can significantly reduce indoor temperature fluctuation, suitable for building energy conservation.

Ascione et al. [12] integrated PCM plaster to the building envelope. The results were simulated varying the phase change temperature, thickness of the wallboard and the location. The achievable benefit for energy savings in climates simulating Seville and Naples was lower than 3\%, while for Marseille and Athens benefit was 4.1 and 3.5\%, 
respectively. The highest energy saving effect was reached in Ankara, with energy savings of $7.2 \%$.

Li et al. [13] investigated thermal performance of PCM on the roof in comparison with regular roof. They also studied the effects of solar radiation intensity, transition temperature and latent heat of PCM, roof slope, PCM layer thickness, and absorption coefficients of external roof surface. Results showed that peak temperature delay of PCM roof was 3 hours. Increasing PCM layer and roof slope decreased the average temperature, heat flux of upper surface in the base layer.

There are a number of studies done on different issues of PCM applications in buildings. The researchers mainly focused on using microencapsulated PCMs for energy saving in buildings. With microencapsulation, the amount of PCM that can be used is decreased and microencapsulation increases the cost. Direct incorporation and immersion techniques are more cost and time effective. However, some existing difficulties hinder the wide spread applications in buildings. Main difficulty of incorporating PCMs directly in building elements is leakage problem. PCM leakage can occur during liquefaction of PCM and during the mixing process of concrete [14]. This causes PCM loss and a reduction of the heat storage capacity of the composite. Therefore, leakage test should be carefully carried out as an important step in developing new PCM composite materials studies.

Various kinds of PCMs such as fatty acids, paraffins, inorganic salts have been studied to be used in buildings . Among them, butyl stearate, an ester, has taken attention with its suitable melting point and high latent heat. Butyl stearate is already used as damp-proofing admixture to improve durability of concrete [15].

In this study, with a new approach, other than its main using purpose as an admixture, butyl stearate was used for enhancing thermal performance of concrete. The objective is to investigate thermal properties of butyl stearate as PCM and direct incorporation into concrete. The ultimate aim is energy saving in buildings with thermally enhanced concrete. Optimal PCM dosage and effects of mechanical strength were determined. PCM leakage from porous structure of concrete was also studied.

\section{EXPERIMENTAL}

\section{A. PCM}

TABLE I: PROPERTIES OF BUTYL STEARATE

\begin{tabular}{ll}
\hline \hline Properties & \\
\hline Grade & technical \\
Assay & $40-60 \%(\mathrm{GC})$ \\
Impurities & butyl palmitate, residual \\
Refractive index & $n 20 / \mathrm{D} 1.443$ \\
Melting Point & $17-22{ }^{\circ} \mathrm{C}$ \\
Flash Point & $160{ }^{\circ} \mathrm{C}$ \\
Density & $0.861 \mathrm{~g} \mathrm{~mL}^{-1}$ at $20{ }^{\circ} \mathrm{C}$ \\
Molecular Weight & $340.58 \mathrm{~g} \mathrm{~mol}^{-1}$ \\
Linear Formula & $\mathrm{CH}_{3}\left(\mathrm{CH}_{2}\right)_{16} \mathrm{COO}\left(\mathrm{CH}_{2}\right)_{3} \mathrm{CH}_{3}$ \\
\hline \hline
\end{tabular}

In this study, direct incorporation of PCM into concrete has been selected to provide a cost effective application.
Technical grade butyl stearate used as PCM was supplied from Sigma Aldrich and used without any further purification. The properties of butyl stearate as given by the supplier are given in Table I.

\section{B. PCM Characterization}

Differential scanning calorimetry (Perkin Elmer Diamond DSC) was used for thermal characterization of butyl stearate (Fig. 1). For DSC analysis, approximately $5 \mathrm{mg}$ of PCM sample was placed in an aluminum pan. The sample was scanned from $10^{\circ} \mathrm{C}$ to $30^{\circ} \mathrm{C}$ at a heating rate of $1^{\circ} \mathrm{C} \mathrm{min}{ }^{-1}$ under inert nitrogen atmosphere with at $20 \mathrm{~mL} / \mathrm{min}$ gas flow rate. Three runs were performed for each sample with the same experimental conditions to ensure repeatability.

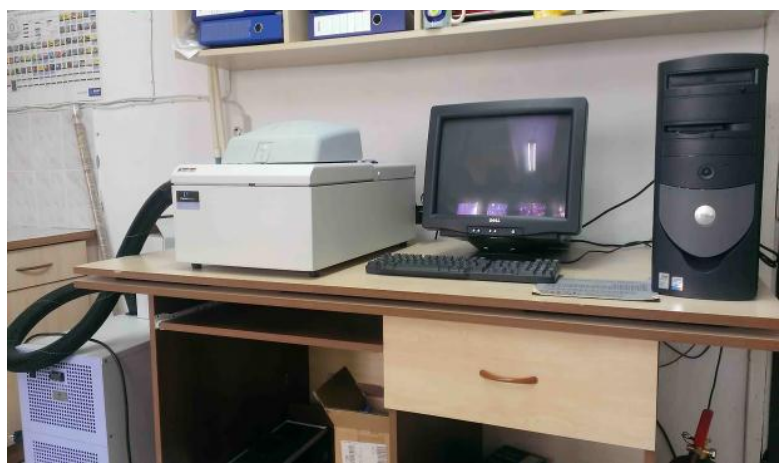

Fig. 1. Differential scanning calorimeter.

The heating/cooling curves of the PCM were obtained using a programmable thermo stated bath (Huber CC) with a heating/cooling rate of $1^{\circ} \mathrm{C} \mathrm{min}{ }^{-1}$ (Fig. 2). Controlled heating and cooling processes were done at temperatures ranging from $5{ }^{\circ} \mathrm{C}$ to $35^{\circ} \mathrm{C}$. Temperature measurements of the $10 \mathrm{ml}$ samples in test tubes, placed in the bath were measured by T-type thermocouples with an accuracy of $\pm 0.5^{\circ} \mathrm{C}$. Measurements were recorded by a data logger (Agilent 34970A Model) at $10 \mathrm{sec}$ intervals.

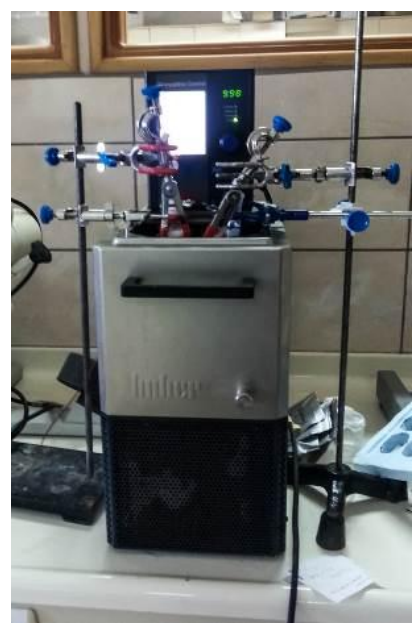

Fig. 2. Experimental setup for heating/cooling curves in waterbath

\section{Long Term Stability of PCM}

Accelerated thermal cycling test was conducted to determine thermal stability of PCM. Cycling stability is one of the key properties of PCMs, since their lifetime depends on it. The tests were carried out first by heating PCM above its melting temperature, followed by cooling below freezing 
temperature using a programmable thermostatic water bath (Huber CC-E).

PCM was subjected to total number of 1000 melting-freezing cycles and any possible change in thermal properties was investigated in every 200 cycles by DSC analysis.

\section{Concrete Mixture}

For the preparation of concrete mixture TS 802 absolute volume method for C40/50 type concrete was used. A self-compacting, high strength concrete was selected as a reference to observe the effect of increasing amounts of PCM on compressive strength. To evaluate this, concrete mixes containing 0\%, 1\%, 3\%, $\% 5$ and 10\% (wt.) PCM dosages were studied.

Concrete mixture consisted of fine and coarse aggregates, cement (Oyak Cimento, CEM II/A-M (P-LL) 42.5 R), water, superplasticizer and water. Polycarboxylate ether (PCE) used here is a common superplasticizer that provides high workability and better strengths at especially low water/cement ratios. Composition of concrete mixture for 1 $\mathrm{m}^{3}$ is given in Table II. As seen on Table II, the aggregate both fine and coarse - was replaced by PCM at fixed cement content. For the reference concrete (\%0 PCM), water/cement ratio was selected as 0.33 . All ingredients were mixed using an electrically driven mechanical mixer (Dinc Makina). First, required amounts of cement, fine and coarse aggregate were mixed, followed by mixing with quantified amount of water and superplasticizer. Finally, PCM was added and mixed for 5 min more. Thereafter, the concrete samples were cast immediately into the molds of dimension $15 \times 15 \times 15 \mathrm{~cm}$.

After 1 day, the concrete specimens were removed from the molds, and cured in water at a temperature of $20 \pm 2^{\circ} \mathrm{C}$ until the age of 7 and 28 days. In order to obtain an optimal curing process, specimens were fully submerged in water baths throughout the process.

TABLE II: COMPOSITION OF CONCRETE MIXTURE FOR $1 \mathrm{M}^{3}$

\begin{tabular}{lcccccc}
\hline \hline & $0 \%$ & $1 \%$ & $2 \%$ & $3 \%$ & $5 \%$ & $10 \%$ \\
\hline PCM (kg) & 4.5 & 4.5 & 4.5 & 4.5 & 4.5 & 4.5 \\
PCE (kg) & 0 & 8.6 & 17.2 & 25.8 & 43.0 & 86.1 \\
$\begin{array}{l}\text { 0-3 crushed fine } \\
\text { aggregates (kg) }\end{array}$ & 1034 & 1019 & 1004 & 988 & 959 & 882 \\
$\begin{array}{l}\text { 5-10 crushed fine } \\
\text { aggregates (kg) }\end{array}$ & 418 & 412 & 406 & 400 & 388 & 357 \\
$\begin{array}{l}\text { 10-20 crushed fine } \\
\text { aggregates (kg) }\end{array}$ & 364 & 359 & 354 & 348 & 338 & 311 \\
$\begin{array}{l}\text { Water (kg) } \\
\text { Cement (kg) }\end{array}$ & 201 & 201 & 200 & 200 & 199 & 197 \\
\hline \hline
\end{tabular}

\section{E. Mechanical Tests}

The compressive strength of the hardened concrete specimens was determined according to TS-EN (2003) 12390-3 standard. The specimens with dimension of $15 \times 15 \times 15 \mathrm{~cm}$ cured for 7 and 28 days were subjected to mechanical testing using a universal test machine (Dinç Makina, D201.A) shown in Fig. 3.

\section{F. Leakage Test}

A filter paper test was carried out to determine any possible leakage during melting of PCM, as described previously by
[5]. For this aim, concrete specimens, with a dimension of $7 \times 7 \times 7 \mathrm{~cm}$ were wrapped by a weighted coarse filter paper. Specimens were heated up in a climate chamber to above the melting temperature of PCM and kept at this temperature for 1 h. Following this heat treatment, samples were cooled in climate chamber to $15^{\circ} \mathrm{C}$ and held at this temperature for another hour. The filter paper was later removed and weighed again to see if there were any wight change as a result of PCM leakages.

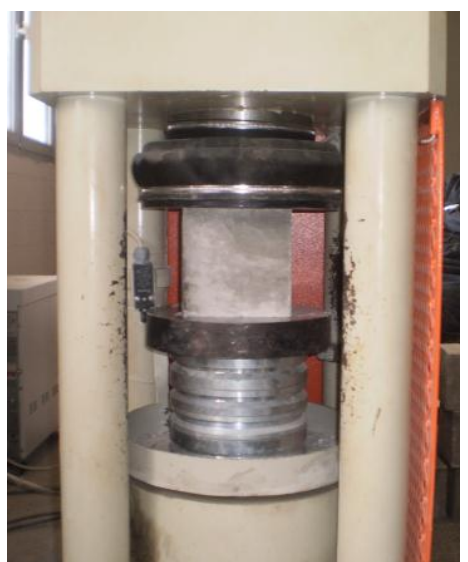

Fig. 3. Universal testing machine for compressive strength test.

\section{RESULTS}

\section{A. PCM Characterization}

DSC curve obtained for butyl stearate is shown in Fig. 4. It can be seen that butyl stearate has a clear phase change peak both melting and freezing. For the melting, an enthalpy of $134.16 \mathrm{~J} / \mathrm{g}$ and melting temperature of $21^{\circ} \mathrm{C}$ (onset) were measured. The melting/freezing points and enthalpies of PCM were suitable for buildings to maintain inside temperature in human comfort zone.

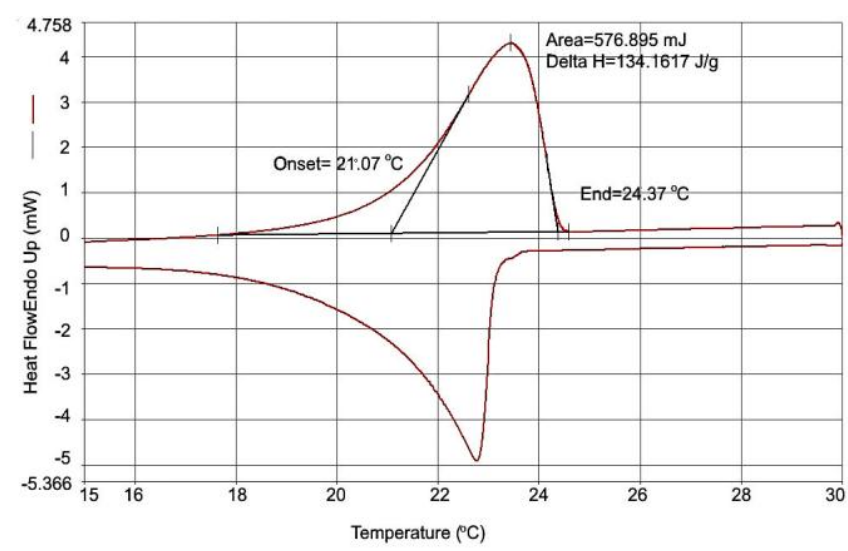

Fig. 4. DSC curve of butyl stearate.

Heating and cooling curves in the water bath and climate chamber were also obtained. Fig. 5 shows heating/cooling curves of butyl stearate. Required sample mass to obtain these curves is much more than DSC analysis. Therefore, thermophysical properties determined from these curves can represent bulk material properties that are used in practical systems better. The melting and freezing ranges encircled are in good agreement with DSC results and no-supercooling was observed. 


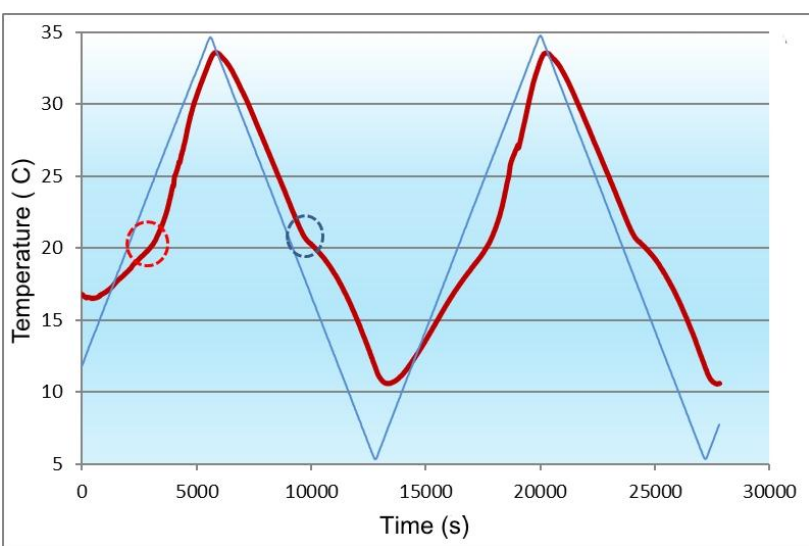

(a)

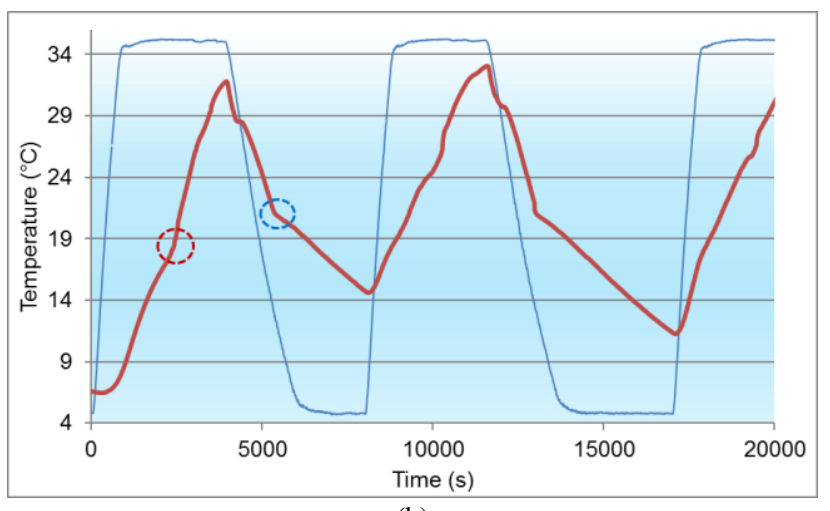

(b)

Fig. 5. Heating/cooling curves of butyl stearate obtained in (a) water bath (b) climate chamber.

\section{B. Long Term Stability of PCM}

DSC curves obtained after every 200 cycles were overlapped in Fig. 6. The changes in melting points and latent heats are summarized in Table III. At the end of 800 cycles, the melting temperature and latent heat storage capacity changed from $21.0^{\circ} \mathrm{C}$ to $20.8^{\circ} \mathrm{C}$ and, from $135.5 \mathrm{~J} / \mathrm{g}$ to 105.1 $\mathrm{J} / \mathrm{g}$, respectively. It can be concluded that there was no significant change in melting temperature, but the change in latent heat was $22 \%$. The change in latent heat storage capacity almost stabilized after 400 thermal cycles.

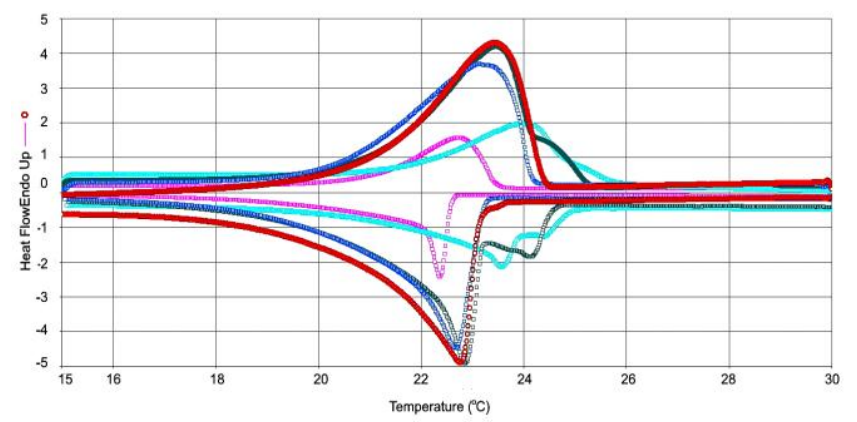

Fig. 6. Comparison of the DSC curves of PCM subjected to $(0,200,400,600$, 800) thermal cycles.

TABLE III: THERMAL CYCLING RESULTS

\begin{tabular}{lcc}
\hline \hline Cycles & $\Delta \mathrm{H}_{\mathrm{m}}(\mathrm{J} / \mathrm{g})$ & $\begin{array}{c}\mathrm{T}_{\mathrm{m}}\left({ }^{\circ} \mathrm{C}\right) \\
\text { (onset-end) }\end{array}$ \\
\hline 0 & 135,5 & $21,0-24,3$ \\
200 & 25,5 & $20,4-24,8$ \\
400 & 98,8 & $20,9-24,0$ \\
600 & 104,4 & $21,2-24,4$ \\
800 & 105,1 & $20,8-24,2$ \\
\hline \hline
\end{tabular}

\section{Mechanical Tests}

The compressive strengths of concrete specimens of various PCM dosages are compared in Fig. 7. As can be seen, the compressive strength is found to be decreasing with increasing amount of PCM. Concrete containing 10\% PCM complied with $\mathrm{C} 20 / 25$ and $5 \%$ complied with $\mathrm{C} 30 / 37$ class of concrete, according to TS EN 206-1. In most building applications, using C30 and higher class of concrete is recommended. Hence, concrete mixtures containing 5\% PCM is recommended as optimum dosage for building application.

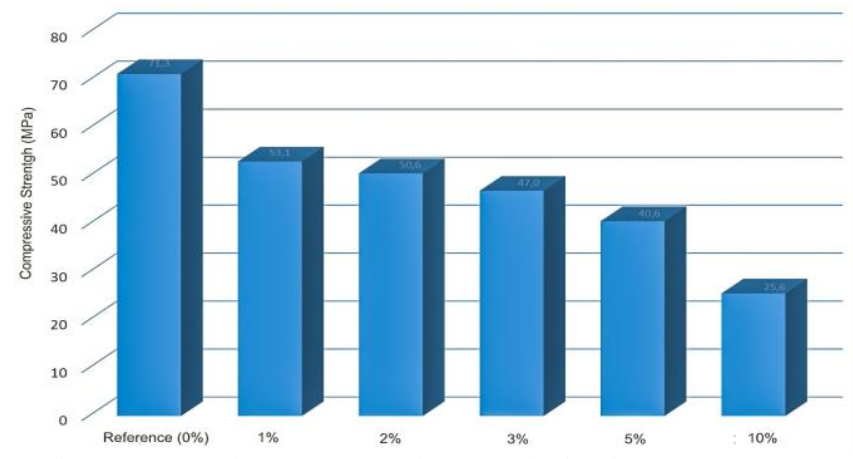

Fig. 7. Comparation on compressive strengh of various PCM dosages.

\section{Leakage Test}

PCM leakage from concrete may occur during the phase change process. As a result of this heat storage capacity of a composite material can be lower [14]. The filter paper test was done for concrete containing $10 \%$ wt. PCM to detect any possible leakage. Results of the tests showed that there was no significant weight change or oil stain on filter paper.

\section{CONCLUSION}

Possible usage of a novel PCM-concrete composite in buildings for energy conversation was investigated here. Direct incorporation of PCM into concrete, which is more cost effective than the other methods, was the focus of the study. Thermal characteristics of the butyl stearate as candidate PCM $\left(\Delta \mathrm{H}_{\mathrm{m}}: 135.5 \mathrm{~J} / \mathrm{g}, \mathrm{Tm}: 21.0^{\circ} \mathrm{C}\right)$ were found to be suitable for using in concrete. Butyl stearate is readily used as concrete additive to improve durability and life time of concrete. We also tested long term stability of butyl stearate as PCM. Thermal cycling test shows that after 800 cycle melting temperature remains constant. The loss of compressive strength was significant with increasing amount of PCM dosage. However, concrete with PCM content up to $5 \%$ wt. accompanying compressive strength of $40 \mathrm{~N} / \mathrm{mm}^{2}$ is higher than the suggested value for most constructional purposes. Results showed that a leakage-free, thermally enhanced composite-concrete can be produced for energy saving in buildings. Further studies are needed to evaluate thermal performance under real climate conditions. For this aim, conducting a field test with a scaled-down test building, which will be constructed using concrete with $5 \%$ butyl stearate is ongoing.

\section{ACKNOWLEDGMENT}

The authors would like to acknowledge the support 
provided by TUBITAK under the Project No 111M557, Çukurova University BAP Project No FDK-2015-3278, FYL-2015-4447 for their funding of this research and also Kambeton Co.

\section{REFERENCES}

[1] A. Grübler and A. McDonald, Global Energy Perspectives, Cambridge University, 1998

[2] G. Grazzini and A. Milazzo, "Thermodynamic analysis of CAES/TES systems for renewable energy plants," Renewable Energy, vol. 33, no. 9, pp. 1998-2006, 2008.

[3] T. Okazaki, Y. Shirai, and T. Nakamura, "Concept study of wind power utilizing direct thermal energy conversion and thermal energy storage," Renewable Energy, vol. 83, pp. 332-338, 2015.

[4] DOE global energy storage database. [Online]. Available: $\mathrm{http}: / /$ www.energystorageexchange.org/projects

[5] K. Cellat, B. Beyhan, C. Güngör, Y. Konuklu, O. Karahan, C. Dündar, and H. Paksoy, "Thermal enhancement of concrete by adding bio-based fatty acids as phase change materials," Energy and Buildings, 2015.

[6] A. M. Borreguero, A. Serrano, I. Garrido, J. F. Rodríguez, and M. Carmona, "Polymeric-SiO 2-PCMs for improving the thermal properties of gypsum applied in energy efficient buildings," Energy Conversion and Management, vol. 87, pp. 138-144, 2014.

[7] M. Karkri, M. Lachheb, F. Albouchi, S. B. Nasrallah, and I. Krupa, "Thermal properties of smart microencapsulated paraffin/plaster composites for the thermal regulation of buildings," Energy and Buildings, vol. 88, pp. 183-192, 2015.

[8] P. Principi and R. Fioretti, "Thermal analysis of the application of PCM and low emissivity coating in hollow bricks," Energy and Buildings, vol. 51, pp. 131-142, 2012.

[9] C. Voelker, O. Kornadt, and M. Ostry, "Temperature reduction due to the application of phase change materials," Energy and Buildings, vol. 40, no. 5, pp. 937-944, 2008

[10] C. Castellón, A. Castell, M. Medrano, I. Martorell, and L. F. Cabeza, "Experimental study of PCM inclusion in different building envelopes," Journal of Solar Energy Engineering, vol. 131, no. 4, 2009.

[11] H. He, Q. Yue, B. Gao, X. Zhang, Q. Li, and Y. Wang, "The effects of compounding conditions on the properties of fatty acids eutectic mixtures as phase change materials," Energy Conversion and Management, vol. 69, pp. 116-121, 2013

[12] F. Ascione, N. Bianco, R. F. de Masi, F. de'Rossi, and G. P. Vanoli, "Energy refurbishment of existing buildings through the use of phase change materials: Energy savings and indoor comfort in the cooling season," Applied Energy, vol. 113, pp. 990-1007, 2014.

[13] D. Li, Y. Zheng, C. Liu, and G. Wu, "Numerical analysis on thermal performance of roof contained PCM of a single residential building," Energy Conversion and Management, vol. 100, pp. 147-156, 2015.

[14] H. Li, H. Chen, X. Li, and J. G. Sanjayan, "Development of thermal energy storage composites and prevention of PCM leakage," Applied Energy, vol. 135, pp. 225-233, 2014.

[15] H. Justnes. (2008). Low water permeability through hydrophobicity. [Online]. Available: https://www.sintef.no/globalassets/upload/byggforsk/publikasjoner/co in-no1.pdf

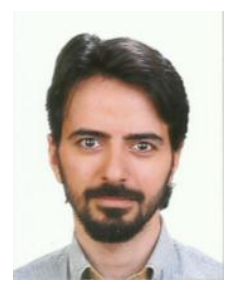

Kemal Cellat was born in Istanbul, Turkey in 1983 $\mathrm{He}$ received the BS degree from Cumhuriyet University, Department of Chemistry, Sivas, Turkey in 2007. He earned his master's degree in analytical chemistry at Cukurova University, Department of Chemistry, Adana, Turkey in 2011. Since 2011, he is studying on thermal energy storage in buildings at Cukurova University as a $\mathrm{PhD}$ candidate.

His recent publications are : 1). K. Cellat, B. Beyhan, C. Güngör, Y. Konuklu, O. Karahan, C. Dündar, H. Paksoy, "Thermal enhancement of concrete by adding bio-based fatty acids as phase change materials," Energy and Buildings, 2015. 2). O. Eren, Ş. Gül, E. Kuşvuran, K. Cellat, F. Mıdık Ertosun, "Treatment of olive mill wastewater by catalytic ozonation using activated carbon prepared from olive stone by
KOH activation," Asian Journal of Chemistry, vol. 27, no. 11 pp 114106-114110, 2015. 3). K. Cellat et al., "Unconventional experimental technologies used for phase change materials (PCM) characterization: Part 2 - morphological and structural characterization, physico-chemical stability and mechanical properties," Renewable and Sustainable Energy Reviews, December 4, 2014.

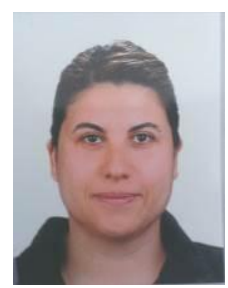

Beyza Beyhan was born in Bolu, Turkey in 1981. She graduated from Chemistry Department of Osmangazi University, Eskisehir, Turkey. She received her master degree in physical chemistry at Cukurova University, Adana, Turkey. Since 2011, she is studying on thermal energy storage at Cukurova University as a PhD candidate.

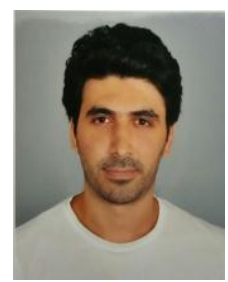

Berk Kazanci was born in Adana, Turkey in 1990 He graduated from F. N. Tekerekoglu High School in Gaziantep, Turkey. He received a B.S. degree in chemistry in 2013 from Cukurova University, Adana, Turkey. He has been studying on thermal energy storage and flammability properties of PCMs at Cukurova University as a MSc student since 2013.

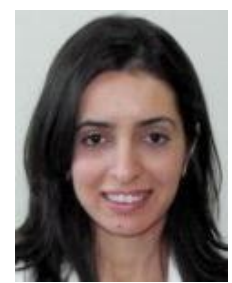

Yeliz Konuklu is an assistant professor at Nigde University, Nigde, Turkey. She is also a researcher at Nigde University, Nanotechnology Application and Research Center. She received her BS degree in 2001 from the Chemistry Department of Cukurova University, Adana, Turkey. She obtained her MSc degree on the microencapsulation of phase change materials (PCMs) in 2004 and her PhD degree on microencapsulated PCMs for energy conservation applications in buildings in physical chemistry in 2008 from Cukurova University. She worked at a chemistry company as an R\&D engineer and outsourcing engineer from 2006 to 2008. She is also a member of the secretariat team of the Executive Committee of IEA-ECES IA since May 2011. Her research interest includes micro-nanoencapsulation of phase change material for thermal energy storage systems. She is also working on preparation natural mineral/phase change material composites. Her research has been supported by The Scientific \& Technical Research Council of Turkey (TUBITAK) and Research Projects Unit of Nigde University. Two special research projects financially supported by the TUBITAK deserve mention: 1) Temperature Controlled Package containing Microencapsulated Phase Change Materials Using in Foods (111M614), 2) Preparation and Characterization of Sepiolite Doped Diatomite/Phase Change Material Composites With Thermal Energy Storage Properties (115M525).

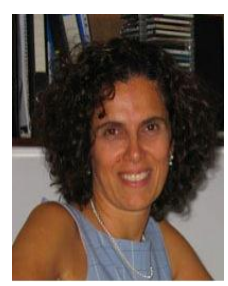

Halime Paksoy was born in Adana, Turkey in 1961 She received a B.S. degree in chemical engineering in 1983 from Bogazici University in Istanbul, Turkey. She obtained the M.S. degree in 1986 and $\mathrm{PhD}$ degree in 1992 in physical chemistry from Çukurova University in Adana, Turkey.

She is currently a professor in the Chemistry Department, and also the director of the Center for Environmental Research at Çukurova University. She has been concentrating on thermal energy storage technologies since 1986 Her main research is on fundamental and applied energy storage studies, as well as on developing thermal energy storage materials.

Dr. Paksoy has directed a NATO advanced study institute on "Thermal Energy Storage for Sustainable Energy Consumption" in June 2005. She is associate editor responsible for energy storage in the International Journal of Solar Energy. She serves as the Turkish delegate and current the chair of the Executive Committee of the Energy Conservation through Energy Storage Implementing Agreement of International Energy Agency. 